Language and Language Teaching Journal http://e-journal.usd.ac.id/index.php/LLT Sanata Dharma University, Yogyakarta, Indonesia

\title{
Speech Acts and the Different Perspectives on the Meaning of "Very Sorry" in the Letter on Hainan Island Incident
}

\author{
Christine Permata Sari \\ Sanata Dharma University \\ permatachristine@yahoo.com \\ DOI: doi.org/10.24071/11t.2017.200102
}

\begin{abstract}
This study aims to analyze the types of speech acts in the text and to analyze different perspectives on the meaning "very sorry" between the United States of America and the People's Republic of China. The object of the study is a letter of saying sorry from the U.S. Ambassador for China Joseph Prueher to the Foreign Minister of the PRC Tang Jiaxuan on the incident in Hainan Island which caused the death of the Chinese's pilot and the custody of the aircraft crew and the surveillance aircraft relating the emergency landing without any prior permission. The researcher employed the speech acts theory proposed by Searle (1979) as cited by Wardhaugh (2006) to analyze speech acts types and to obtain the dominant type and the implication used in the text. The strategies of apology by Cohen and Olshtain (1986) as cited by Zhang (2001) were also employed. This study is descriptive qualitative research. The result showed the biggest percentages of the types were expressive and assertive. The researcher also found the different perspectives on the meaning of "very sorry" between the US and the PRC which led into misunderstanding influenced by the culture. This research benefits the English language learners to understand the meaning of locutions which they hear and to acknowledge the culture influences society perspectives in understanding the meaning especially for nonEnglish speakers.
\end{abstract}

Keywords: speech acts, the meaning of 'sorry', Hainan Island incident

\section{Introduction}

According to Wardhaugh (2006) the functions of many utterances are to make propositions. According to Cambridge Dictionary $3{ }^{\text {rd }}$ Edition, proposition itself is an idea or opinion. Meaning to say, no utterance is uttered without purposes. There are some ideas underlying the utterance or there is a meaning behind every utterance. The form can be a statement or a question. The purpose of pragmatic study is to obtain meaning of utterances in context and to study how language is used. Sometimes it is concerned with the interpretation of linguistic meaning in context. Pragmatics is the study on how speakers of a language use sentences to produce successful communication. It makes the English learners be more aware of socio cultural. Moreover, for non-native speakers, it is difficult to understand the intended meaning in English utterances and to produce a speech act using appropriate manner and language. According to Salgado (2011) non-native speakers' (NNSs') pragmatic knowledge differs from that of native speakers (NSs) (Blum-Kulka, 1982; Blum-Kulka and Olshtain,1986; Blum-Kulka and Kasper, 1989; Faerch and Kasper, 1989; Yu, 1999). In addition, speech acts learning becomes more interesting regarding cross-cultural pragmatics. The 
findings from a cross-cultural study by Cohen, Olshtain, and Rosenstein (1986) as cited by Salgado (2011) showed that non-native speakers (NNS) were not aware to certain sociolinguistic distinction compared to native speakers (NS) who were aware with that.

The object of this study is the letter from the U.S. Ambassador named Joseph Prueher to Tang Jiaxuan, Foreign Minister of the People's Republic of China to resolve the "spy plane crisis" on April 1 ${ }^{\text {st }}, 2001$. After a collision between the U.S. surveillance aircraft EP-3 and a Chinese fighter J8II, the U.S. aircraft made an emergency landing on Hainan Island, China. The American aircraft sustained damage to a wing and the engine, declared an emergency, and landed-without prior permission - at the nearest airstrip, on a military base in China's Hainan Province. According to Kuhn (2010) the Chinese jet disintegrated and went down into the ocean. The pilot was descending with an open parachute, but was never found and was presumed dead. The delivery of the letter was made in order to the obtain the release of the U.S. crew from Chinese captivity, as well as the return of the US aircraft even though it had to be disassembled and carried by a Russian aircraft. Unfortunately, the letter was made on April 11 ${ }^{\text {th }}, 2011$ and not directly after the incident occurred. It showed that the U.S government did not take responsibility for the incident. The main reason why the letter was eventually made was because the PRC did not want to return the US aircraft until there was an official apology from the U.S. government. It can be assumed that if the PRC returned the aircraft without any conditions, the letter on Hainan Incident would not have been made.

The objective of this study is to analyze and examine the kinds of utterances used by the US government in delivering their sorry, or their expression of regret, using Searle's analysis of speech act categories. Searle's speech act categories were used to analyze the whole parts of the object linguistically by examining the clauses. The researcher would essentially like to scrutinize the locutions in the letter and also to show the cultural differences in responding and saying sorry because the United States of America and the People's Republic of China had different opinions in their perception of the letter's meaning. The researcher also used the strategies of apology proposed by Cohen and Olshtain (1986) as cited by Zhang (2001) to show the different ideology of apologizing. The People's Republic of China felt superior to the US because the US apologized to them by saying sorry twice in the letter. In the US' point of view, they did not apologize to them about what they had done. The word 'sorry' in the letter was only meant as an expression of sadness, sympathy, or disappointment.

Using the theories above, the implication or the hidden meaning of the letter can be revealed because it is about the political issue where a powerful country will be considered weak by apologizing. On the other hand, the weaker country does not want to look weak by simply allowing the stronger country to trespass in its area without any verbal or written clearance.

There are four research questions discussed in this paper. First, what kinds of speech acts are mostly found in the letter regarding the Hainan island incident on April 1, 2001? Second, what are the dominant types of speech acts in the entire letter? Third, what are the implications of using these speech acts? Fourth, what 
are the different perspectives on the meaning "very sorry" between the United States of America and the People's Republic of China?

\section{Method}

The object of the study is the text of the letter written by U.S. Ambassador to China Joseph W. Prueher to Chinese Foreign Minister, Tang Jiaxuan, for the Hainan Island incident on April 1at, 2001. In the text, there are 12 sentences, and after being divided based on subject and verb agreement, there are 17 clauses. This categorization process was done to make the analysis of each locution/ utterance easier to see main purpose of the letter from the whole text.

This paper uses a descriptive qualitative method. According to Glass \& Hopkin (1884), the descriptive approach can be either quantitative or qualitative. It can involve collections of quantitative information that can be tabulated along a continuum in numerical form.

In this research, the researcher did the numeric calculation according to the text which was analyzed to see the presentation from the highest to the lowest percentages. This was to answer the research questions especially question number one.

In analyzing the data, firstly, the researcher read all the text, and then divided the sentences into some clauses according to the subject and verb agreement. Afterwards, the researcher examined all the utterances, especially the structure, and then the researcher classified each locution into the category of speech act to see the types of speech mostly used in the letter and also to determine which type which was most dominant in the paper. Afterwards, the researcher analyzed the word 'very sorry' using the strategies of making an apology (Cohen and Olshtain, 1986) as cited by Zhang (2001) to see the ideology of apologizing.

\section{Results and Discussion}

The discussion is divided into two parts, the first part is about the types of speech acts used in the text, which type is dominant, and the implication of using certain types of speech acts. The first part is to answer the question number 1 . The second part is about how the different perception towards the word 'sorry' in the text can emerge between the U.S. of America and the PRC. The researcher analyzes the different perspectives of those two big countries towards the same thing specifically the meaning of the words "Very Sorry". The researcher will to answer question 3 in this part.

\section{Types of Speech Acts}

The letter has been analyzed using types of speech acts proposed by Searle. There are 17 clauses which are categorized into several types of speech acts according to the meaning in the context.

Table 1: Types of speech acts used in the letter

\begin{tabular}{|l|l|c|c|}
\hline No. & Types of Speech Act & Number & Percentages \\
\hline 1. & Assertive & 6 & $35.3 \%$ \\
\hline 2. & Commisive & 2 & $11.8 \%$ \\
\hline
\end{tabular}




\begin{tabular}{|l|l|c|c|}
\hline 3. & Declaratives & 1 & $5.9 \%$ \\
\hline 4. & Directives & 2 & $11.8 \%$ \\
\hline 5. & Expressive & 6 & $35.3 \%$ \\
\hline & & 17 & $100 \%$ \\
\hline
\end{tabular}

As the results mentioned in the table, the letter includes all types of speech acts which are assertive, directives, commissives, expressive, and declaratives. However, each of them has different percentages. The most dominant types are assertive and expressive. Both of them are 35.3\%.After examining the letter, we can see that most of them are explanations of how and why the incident incurred.

The assertive are dominant because the US government mostly used the letter to explain how the incident could have happened and how to solve the case. There are 6 utterances which use assertive.

"Although the full picture of what transpired is still unclear, according to our information, our severely crippled aircraft made an emergency landing after following international emergency procedures." $(5-6)$

From the locution above, the US government explained or informed the reason why their aircraft made an emergency landing at Lingshui airfield, Hainan, China. As mentioned in the introduction part, US Navy EP3E ARIES II flew over China's airspace. The Chinese government thought it was a surveillance aircraft, so that the EP3 got shot down by People's Liberation Army Navy (PLAN) J8II interceptor fighter jet. The other assertive form found in utterance

"The meeting agenda would include discussion of the causes of the incident, possible recommendations whereby such collisions could be avoided in the future, development of a plan for prompt return of the EP-3 aircraft, and other related issues."

This locution above states that the US government notified PRC government about the meeting and what would be discussed in the meeting. It is because there was an international dispute between the US and the PRC over the legality of the over-flights by the US naval aircraft. The area is part of the PRC's exclusive economic zone based on the United Nations Convention on the Law of the Sea. The PRC signed this Convention, while the United States had not. The PRC interprets the Convention as allowing it to preclude other nations' military operations within this area, but the United States maintains that the Convention grants free navigation for all countries' aircraft and ships, including military aircraft and ships, within a country's exclusive economic zone. In addition, according to the letter, the discussion would also address the topic of returning the EP-3 since the PRC did not agree to return the aircraft to the US until they apologized to PRC. The PRC wanted the US to say sorry to them because they had a slow response towards the incident. It took more than 7 days to respond and show their responsibility to the PRC. The incident was on April $1^{\text {st }}, 2001$, while the letter was delivered on April $11^{\text {th }} 2001$. Eventually the EP-3 aircraft was returned back to the US, but the PRC did not allow flying off Hainan Island. The disassembled aircraft was released on July 3, 2001, and was returned by the Russian airline Polet in an Antonov An-124 aircraft. 
Another type of speech act which is dominant is expressive. Actually it is obvious that the letter was sent to express the sadness feeling of the US government towards the Hainan Island incident.

"..... that we are very sorry for their loss." (4)

"We are very sorry (the entering of China's airspace and the landing did not have verbal clearance)" (7-8)

From the utterances above, we can see that the US government felt bad to the incident. It is the core of the letter because the PRC were waiting for a response. There were two focuses in the letter. The first was to express condolences towards the loss of the J8II pilot named Wang Wei. They also expressed their sadness for entering China's airspace without any permission. The use of the words 'very sorry' explains that the US government felt sad over the incident. However, there is something peculiar between the words 'very sorry' since the US government did not forthrightly make an apology in regard to the incident. If we look at the context, pragmatically those words were only used to express the feeling of sadness. Meanwhile, the PRC side accepted the apology from the US. At the end, the words 'very sorry' were confusing and created a misleading perception among the PRC especially the media. In addition, The United States stated that it was "not a letter of apology," as some state-run Chinese media characterized it at the time. It was "an expression of regret and sorrow". The PRC had originally asked for an apology. Unfortunately, the U.S. explained that they did not do anything wrong, and thus it was impossible to apologize on something that they did not do. The details of the reasons for misleading the perception will be explained in the second part.

The smallest percentage of speech acts' types was the declarative type. In the letter, the declarative type was used in the first line

"On behalf of the United States government, I now outline steps to resolve this issue."

Actually, the locution can be considered as assertive since it states something. However, it is considered as declarative type because it meets the features of a declarative which are using the first person singular, speech act verbs, the present tense and active voice. According to Kreidler (1998) the declarative is neither true nor false but its purpose is to make a part of the world conform to what is said. Through the utterance in the letter, eventually the US government wanted to declare that the US took steps to solve the problems by holding a meeting to discuss the causes of the incident, possible recommendations, and the development of a plan for prompt return of the EP3 aircraft;

\section{Meanings of "very sorry" between the US and the PRC}

According to Norman Fairclough (1995) as cited by Zhang (2001) language is a material form of ideology, and is invested by it. Ideology emerges in linguistics form and in discourse. However, the ideology of a certain issue is influenced by the culture specifically in this case is an apology. According to the Guardian news the U.S. President W. Bush and the secretary of state, Colin Powell, expressed "sincere regret" over the loss of the Chinese plane and the missing pilot, Wang 
Wei. The meaning of the first words 'very sorry' was not to apologize. According to Cambridge Dictionary ( $3{ }^{\text {rd }}$ Edition), the 'sorry' is the expression of sadness, sympathy for unpleasant incident has been done. The U.S. response to the incident was to express their sadness. According to the strategy of making an apology proposed by Cohen and Olshtain (1986) as cited by Zhang (2001) such as Illocutionary Force Indicating Device (IFID), an offer of repair (REFR), an explanation of an account (EXPL), acknowledging responsibility for the offense (RESP), and a promise of forbearance (FORB), the letter did not cover any strategies. Even though there were two 'very sorry', the meaning of those words was not significant. It is only expression sadness which does not include in any category.

At first they did not want to take the responsibility since it took some days for them to issue the letter to the PRC government. The trigger was that the PRC did not want to return the U.S. surveillance aircraft. Taking responsibility for the incident would have had serious consequences for the US government in its domestic politics because any admission of guilt would be perceived as weakness by the American people. It was very important for the U.S. to make it seem like they were apologizing without actually apologizing, in order for them to secure the return of their aircraft and its crew. This is where the different perspectives of apologizing are important. By expressing regret to the Chinese government and the family of the pilot, the U.S was doing what was necessary to get what it wanted. This kind of apologizing can be seen in every day American culture where people often apologize for things without actually feeling any sense of regret or without actually feeling sorry. Saying sorry is purely something that is expected by society and is a demonstration of politeness rather than an expression of regret. An example of this occurring might be in the supermarket where a person apologizes to another person for almost bumping into them with their trolley despite that fact that the other person is actually at fault for carelessly stepping backwards into the way of the first person. Another example might be when an employee in a supermarket apologizes on behalf of the supermarket for running out of stock; in actual fact, the employee does not feel any sense of responsibility and he may not even be obliged to apologize by company policy, but he may still apologize because he feels that the customer expects him to do so.

To the Americans, this "apology" was just as routine/ casual as these other meaningless, daily apologies found in American culture. The function of these expressions is to demonstrate politeness or as a means to achieve some other interest, rather than an admission of guilt. If the US did not have an interest in China, then this incident would probably have been a non-issue as the US could have just ignored any requests for an apology. Cleeland (2001) as cited by Zhang (2001) stated that the U.S should issue a fake apology and retract it when they got the crew back. Others also suggested the US should give China what they wanted in exchange for the aircraft crew members. We can see that the type of apology expressed by the US was mundane like in the context of every day politeness. 


\section{Conclusion}

Examining the types of speech acts in the letter from the US to the PRC due to the Hainan Island Incident, the researcher found the biggest percentages of speech acts types were expressives and assertive. Those types got the equal percentage and the implication of using those types was that to inform the significant matters to the PRC government, the solution, and further discussion related to the incident. It was also to expresses the sadness in regard to the incident. The researcher also found the different perspectives on the meaning of "very sorry" between the US and the PRC which led into misperception and misunderstanding. It was also because of the different ideologies of apologizing and it was influenced by linguistic forms from across the languages. At the end the Chinese people considered that the letter was not as serious and humble as it should have been For the Americans, the apology was not serious as it was a demonstration of politeness to achieve another means. While they were saying it, they did not really mean it. It was just a formality. The most important point reason for why the US said sorry was because they had a hidden agenda which was the return of the injured crew members and the crippled aircraft itself. After they got what they wanted, the apology could be retracted.

\section{References}

Kreidler, C. W. (1998). Introducing English semantics. London: Routledge.

Kuhn, R. L. (2010). The inside story of China's reform and what this means for the future: How China's leaders think. Singapore: John Wiley \& Sons (Asia) Pte Ltd.

Salgado, E. F. (2011). The pragmatics of requests and apologies: Developmental patterns of Mexican students. Amsterdam: John Benjamins Publishing Company.

The Guardian. (2001). US says sorry, China to free crew. April 11, 2001. Retrieved from http://www.theguardian.com/world/2001/apr/11/china.usa on 1 June 2016.

Wardhaugh, R. (2006). An introduction to sociolinguistics. Oxford: Blackwell Publishing.

Zhang, H. (2001). Culture and apology: the Hainan island incident. Oxford: Blackwell Publishers. 